\title{
Gestão do Armazenamento e Disponibilidade de Água: Um comparativo entre a região Centro Sul Cearense e a Nordeste Gaúcha
}

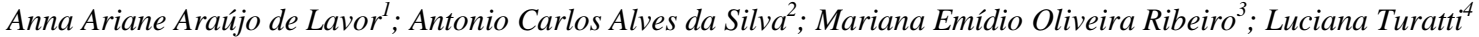

Resumo: O presente artigo relata uma comparação entre duas regiões distintas do país, compreendendo que o Brasil é um país continental e que a condição do semiárido nordestino é bem peculiar em relação às demais regiões como é o caso do Rio Grande do Sul. Deste modo, foram levantados dados das políticas de armazenamento de água das regiões Nordeste e Sul do Brasil. No estudo de caso em questão, os resultados das pesquisas demonstraram que a capacidade máxima das bacias que abastecem Caxias do Sul é de 62.435.920,70 $\mathrm{m}^{3}$, para uma população de 435.564 hab, já os município de Icó e Orós são abastecidos por dois reservatórios que totalizam $2.166 .382 .000 \mathrm{~m}^{3}$ de capacidade, abastecendo uma população de 86.845 hab. Comparando a quantidade de reserva máxima de água por habitante, encontra-se a seguinte proporção $24.945,39 \mathrm{~m}^{3} / \mathrm{hab}$ no Ceará e $143,34 \mathrm{~m}^{3} / \mathrm{hab}$ no Rio Grande do Sul. Neste sentido foi verificado as diferenças nas políticas de gestão dos recursos hídricos com a disponibilização para a população. A principal diferença no planejamento e gestão no armazenamento de água nas duas regiões se deve aos longos períodos de estiagem na região Nordeste, enquanto as chuvas na região Sul ocorrem com mais regularidade durante o ano, havendo a necessidade de armazenamento de uma quantidade de água muito maior por período de tempo que pode ser de vários anos.

Palavras-chave:Abastecimento, Água, Nordeste, Semiárido

\section{Water Storage and Availability Management: A comparison between the Centro Sul Cearense region and the Northeast of Rio Grande do Sul}

\begin{abstract}
The present article reports a comparison between two distinct regions of the country, understanding that Brazil is a continental country and that the condition of the northeastern semi-arid region is very peculiar in relation to the other regions such as Rio Grande do Sul. Data from the water storage policies of the Northeast and Southern regions of Brazil. In the case study in question, the results of the surveys showed that the maximum capacity of the basins that supply Caxias do Sul is $62,435,920.70 \mathrm{~m}^{3}$ for a population of 435,564 inhabitants, while the municipalities of Icó and Orós are supplied by two reservoirs Which total $2.166 .382 .000 \mathrm{~m}^{3}$ of capacity, supplying a population of $86,845 \mathrm{hab}$. Comparing the maximum amount of water per inhabitant, the following proportion is $24,945.39 \mathrm{~m}^{3} /$ inhabitant in Ceará and $143.34 \mathrm{~m}^{3}$ / inhabitant in Rio Grande do Sul. In this sense, it was verified the differences in the water resources management policies with Availability to the population. The main difference in the planning and management of water storage in the two regions is due to the long periods of drought in the Northeast region, while the rainfall in the South region occurs more regularly during the year, and there is a need to store a large amount of water For a period of time that may be several years.
\end{abstract}

Keywords: Supply, Water, Northeast, Semi-arid.

\footnotetext{
${ }^{1}$ Mestranda em Ambiente e Desenvolvimento pala UNIVATES. Contato: annaariane@ hotmail.com;

${ }^{2}$ Mestrando em Ambiente e Desenvolvimento pala UNIVATES. Contato: acas-acas@ hotmail.com;

${ }^{3}$ Mestranda em Ambiente e Desenvolvimento pala UNIVATES. Contato: mariana_meo@hotmail.com;

${ }^{4}$ Doutorado em Direito pela UNISC. Docente do Programa de Pós-Graduação em Ambiente e Desenvolvimento pala UNIVATES. Contato: lucianat@univates.br
} 


\section{Introdução}

A história da humanidade sempre esteve ligada as formas que nos relacionamos com os elementos do meio ambiente, em especial com o uso da água. A cada momento histórico e em cada civilização é possível observar as diferentes formas utilizadas para o consumo de água. Segundo Piterman e Greco (2005), desde as épocas mais remotas, as comunidades se estabeleceram próximas a uma fonte de abastecimento de água, sendo, até os dias de hoje, uma condição de sobrevivência das mesmas.

Neste trabalho foram abordadas as políticas de gestão duas regiões distintas do país, compreendendo que o Brasil é um país continental e que a condição do semiárido nordestino é bem peculiar em relação às demais regiões como é o caso do Rio Grande do Sul. Deste modo, foram levantados dados de duas regiões específicas, na região Nordeste, os municípios de Icó e Orós no estado do Ceará que são abastecidos por dois açudes, na região Sul, o município de Caxias do Sul no Rio Grande do Sul que é abastecido nove reservatórios, onde serão analisados as principais diferenças entre as políticas de gestão no armazenamento da água, e qual a influência das condições meteorológicas de cada região.

Neste presente artigo pode-se visualizar a evolução da relação do homem com a natureza, a fim de que possamos compreender que mesmo atualmente e dentro do Brasil, existem diferentes formas de se encarar esta conexão, considerando problemas que historicamente afligem a população e como função da gestão pública está o enfrentamento destes problemas por meio de planejamentos que muitas vezes ultrapassam seus mandatos eletivos, podendo ocorrer inclusive ganho político dos sucessores e não dos atuais governantes.Tornando uma barreira para implantação de projetos de longo prazo, deste modo os resultados obtidos por meio da pesquisa bibliográfica e documental, serão analisados de modo a verificar como a gestão do armazenamento de água é realizado nestas duas localidades.

Para responder a problemática deste artigo, que por sua vez é verificar como as distintas formas de armazenamento e disponibilidade de água pode influenciar no planejamento público de acordo com os fatores climáticos específicos locais, foi realizada uma pesquisa qualitativa, onde para Chemin $(2015$, p. 56) uma pesquisa qualitativa deve se 
tratar de uma "investigação de valores, atitudes, percepções e motivações do público pesquisado, com o objetivo principal de compreendê-los em profundidade".

Para tanto foi necessário fazer uma pesquisa documental, pois serão realizados buscas em arquivos de dados governamentais sobre as condições de armazenamento de água e disponibilidade da mesma para a população, e também uma pesquisa descritiva, uma vez que este tipo de pesquisa tem em vista "descrever as características de determinada população ou fenômeno, ou estabelecer relações entre variáveis" (CHEMIN, 2015, p. 58)

Portanto foi realizado um estudo de caso que foi comparado duas regiões distintas do Brasil, uma localizada no Sul e a outra no Nordeste. Procurando verificar quais as principais políticas de gestão no armazenamento de água para o abastecimento humano e das atividades econômicas, considerando as especificidade de cada região. Deste modo pretende-se distinguir as diferenças nestas políticas, com o intuito de compreender os investimentos públicos para o atendimento da demanda da população.

\section{Procedimentos Metodológicos}

Tendo em vista que este trabalho buscou obter a percepção das estratégias de gestão do armazenamento e disponibilidade de água para a população, foi necessário utilizar dos seguintes procedimentos metodológicos.

Neste sentido, foi verificado que a pesquisa qualitativa é a que melhor se identifica com a análise do problema proposto, onde para Chemin $(2015$, p. 56) uma pesquisa qualitativa deve se tratar de uma "investigação de valores, atitudes, percepções e motivações do público pesquisado, com o objetivo principal de compreendê-los em profundidade".

Para tanto foi realizada uma pesquisa bibliográfica, exploratória e descritiva. Uma vez que "este tipo de pesquisa tem em vista favorecer a familiaridade, o aumento da experiência e uma melhor compreensão do problema a ser investigado" além de "descrever as características de determinada população ou fenômeno, ou estabelecer relações entre variáveis" (CHEMIN, 2015, p. 58), pois houve necessidade de verificar e descrever diversas situações para permitir uma análise e reflexão com maior clareza da situação de armazenamento de água, principalmente na região do nordeste brasileiro. 
Portanto a pesquisa se caracteriza como um estudo de caso, com o intuito de conhecer um determinado grupo de pessoas ou região e suas características peculiares. Tendo como problema de pesquisa a verificação de quais as principais políticas de gestão no armazenamento de água para o abastecimento humano e das atividades econômicas, considerando as especificidade de cada região. Deste modo pretende-se distinguir as diferenças nestas políticas, com o intuito de compreender os investimentos públicos para o atendimento da demanda da população.

\section{Breve História da Relação dos Seres Humanos com Água}

O primeiro sistema de distribuição de água que se tem registros históricos surgiu há cerca de 4.500 anos (PINTO-COELHO e HAVENS, 2015). No entanto, o homem, bem antes, aprendeu a armazenar a água para benefício próprio, por exemplo por meio de potes de barro não cozidos, os quais surgiram em meados de de 9.000 a.C. A cerâmica, propriamente dita, aparece em 7.000 a.C., e passa a ser fundamental para o incremento da capacidade de armazenamento de água. (PITERMAN e GRECO, 2005)

Os primeiros poços, chafarizes, barragens e aquedutos que se têm notícia foram construídos no Egito, Mesopotâmia e Grécia, em meados de 5.000 - 4.000 a.C.

É de longa data os problemas causados pela poluição dos recursos hídricos, prova disso encontra-se no fato de haver previsão de punição nos textos sagrados persas.

Em 2.000 a.C., a poluição dos recursos hídricos era punida entre os persas e em seus textos sagrados de Avesta, Zoroastro fala sobre cuidados com água, higiene e a saúde (LORETO, 2014). Ainda segundo Loteto (2014), deste mesmo ano, datam os mais antigos escritos em sânscrito sobre os cuidados com a água de consumo, tais como seu armazenamento em vasos de cobre, sua exposição ao sol e filtração através do carvão; a purificação da água pela fervura ao fogo, aquecimento ao sol ou a introdução de uma barra de ferro aquecida na massa líquida, seguida por filtração através de areia e cascalho grosso.

Na filosofia, Platão (427-347 a.C.) destacava a necessidade de disciplinar o uso da água, ele chegou a sugerir algumas penalizações para aqueles que causassem algum dano a um recurso por ele considerado essencial para a manutenção das plantações (Arruda, 1977). 
Com o passar dos anos e com o crescimento das civilizações, estas passaram a ter necessidade de armazenar água em grande escala e neste contexto, os romanos foram os primeiros a realizar construções que permitissem este acondicionamento, o qual era feito através de uma vasta rede de aquedutos que traziam água dos montes até a cidade, por meio de tanques e filtros espalhados ao longo do trajeto.

A demanda e o desperdício de água naquele período eram exorbitantes, consumiam-se milhões de litros de água por dia, por exemplo nos mais de 300 banhos públicos existentes em Roma, por volta do ano 300 d. C. E, segundo Cardoso (2004), manter este dispêndio só era possível graças aos aquedutos.

Sistemas mais complexos de abastecimento de água só vieram a ser construídos por volta do ano 1500, na Alemanha, os quais elevavam a água até torres altas, de onde eram canalizadas.

Neste mesmo período, no Brasil pré-“descobrimento”, as tribos indígenas a deslocarse em busca de alimento e água e não possuíam preocupações complexas sobre abastecimento e saneamento. E após o "descobrimento", a abundância destes mesmos recursos hídricos e utilização de mão de obra escrava para o seu transporte e armazenamento fizeram com que os sistemas de abastecimento de água não fossem implantados durante os três primeiros séculos da colonização no Brasil (PITERMAN e GRECO, 2005).

Nesta época, auge das colonizações, podemos observar grande destaque para o uso da água por meio das grandes navegações, que possibilitaram o apogeu das monarquias de Portugal e Espanha, através de conquistas de vastos territórios nas Américas, na África e na Ásia.

Em seguida a água volta a impulsionar a economia, ao se tornar a força motriz dos engenhos, possibilitando o primeiro grande ciclo econômico das Américas: a produção e exportação da cana de açúcar. (PITERMAN e GRECO, 2005).

Anos depois, com a invenção da máquina a vapor, a água mais uma vez é protagonista da economia, ao possibilitar o emprego de bombeamento com capacidade e potência adequadas. Esta mudança assinalou a passagem da sociedade rural para a sociedade industrial, a mudança do trabalho artesanal para o trabalho assalariado, a utilização da energia a vapor no sistema fabril em lugar da energia humana. (ARRUDA, 1977) 
O crescimento econômico, contudo, não gerou real desenvolvimento, pois a população encontra-se em precária situação de higiene e qualidade da água, o que segundo Arruda (1977) "acarretou a disseminação de epidemias despertando na sociedade a consciência da relação entre o aglomerado de fábricas, moradias e falta de saneamento adequado".

Mas esta conscientização não impediu, que nos séculos mais recentes, a humanidade utilizasse de forma ainda mais demasiada os recursos hídricos do Planeta. E um dos usos da água que mais cresceu no século XX foi através da energia potencial da água para a produção da hidroeletricidade (PINTO-COELHO e HAVENS, 2015), sob o argumento de que seria totalmente limpa e sustentável. Contudo, com o passar do tempo, foi possível observar que as hidrelétricas causam grandes impactos ambientais (mudanças climáticas, desaparecimento de espécies de peixes, fuga desordenada de animais em busca de refúgios secos, árvores viram madeira podre debaixo da inundação) e sociais (deslocamento compulsórios de milhares de pessoas), causando uma pegada ecológica sem precedentes.

Assim, para Pinto-Coelho e Havens (2015), o século XXI chega com uma triste perspectiva em relação ao futuro dos recursos hídricos, pois alguns dos problemas com a água aparentam ter chegado a um ponto talvez irreversível, causados pela globalização da industrialização.

A cada dia, a humanidade se depara com inúmeras doenças infecciosas transmitidas direta ou indiretamente através das águas e muitas populações vêm enfrentando uma crescente escassez de abastecimento de água pura.

Segundo Leff (2009), a crise ambiental é uma crise da razão, do pensamento, do conhecimento, portanto, analisar esta perspectiva histórica nos leva a refletir sobre a recuperação e mitigação dos impactos ambientais, especialmente nas águas do Planeta. Assim, para contribuir com este assunto, far-se-á a seguir um comparativo sobre o uso e armazenamento de água em regiões bem distintas do Brasil, pois a esta diversidade contribuirá na compreensão da complexidade ambiental, que é feita através de um processo de construção de saberes a partir da diferença do ser (LEFF, 2009). 
Id on Line Revista Multidisciplinar e de Psicoloqia

Id on Line Multidisciplinary and Psycology Journal

\section{Bacias Hidrográficas e Disponibilidade de Água}

Ao fazer um comparativo entre duas regiões bem distintas, como é o caso das regiões Nordeste e Sul do Brasil, neste trabalho foram escolhidas duas microrregiões que representam bem as diferenças quanto ao armazenamento de e disponibilidade de água.

Neste sentido foram utilizados o município de Caxias do Sul, que está inserido na microrregião nordeste do Rio Grande do Sul e os municípios de Icó e Orós que estão localizados na região centro sul do Ceará. Segue abaixo um comparativo entre eles.

\section{Caxias do Sul/RS}

Para abastecer uma população de 435.564hab o município conta com nove bacias com capacidade máxima de 62.435.920,70 ${ }^{3}$, ressalta-se que de acordo com a Samae Caxias a evaporação média anual dos reservatórios é de $224 \mathrm{~L} / \mathrm{s}$ de todos os reservatórios juntos. Vale destacar ainda que a barragem mais antiga é a de São Paulo, localizada na bacia Dal Bó, a sua construção data de 1928, e a barragem mais nova é a bacia Marrecas, inaugurada em 2012 sendo a maior bacia de Caxias do Sul com 29.950.375,90m³.

Segue abaixo mais algumas informações sobre os reservatórios de Caxias do Sul:

Figura 1: Bacias Hidrográficas de captação de Caxias do Sul

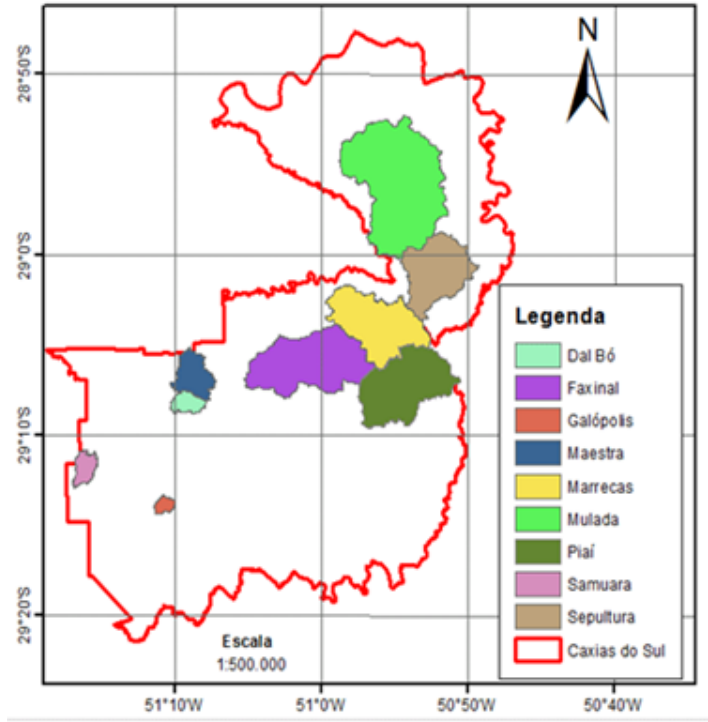

Fonte: SAMAECaxias (2017) 
Id on Line Revista Multidisciplinar e de Psicoloqia

Id on Line Multidisciplinary and Psycology Journal

\section{Orós e Icó/CE}

As duas cidades são abastecidas por dois reservatórios, sendo a mais antiga a Barragem do Açude Lima Campos, sendo instalado em 1932 com capacidade instalada de 66.382.000 $\mathrm{m}^{3}$, onde atualmente abastece apenas o distrito de Lima Campos e o perímetro irrigado de Icó. Já o segundo, conhecido como Açude Orós, mas como o nome oficial de Barragem Presidente Juscelino Kubitschek de Oliveira, inaugurado em 1961 com a capacidade máxima de $2.100 .000 .000 \mathrm{~m}^{3}$, ou seja, a soma dos dois reservatórios somam 2.166.382.000 $\mathrm{m}^{3}$, considerando que a população dos municípios de Orós e Icó correspondem a 21.389 hab e 65.456 hab respectivamente, totalizando 86.845 hab.

Figura 2: Bacias Hidrográficas de Orós e Lima Campos

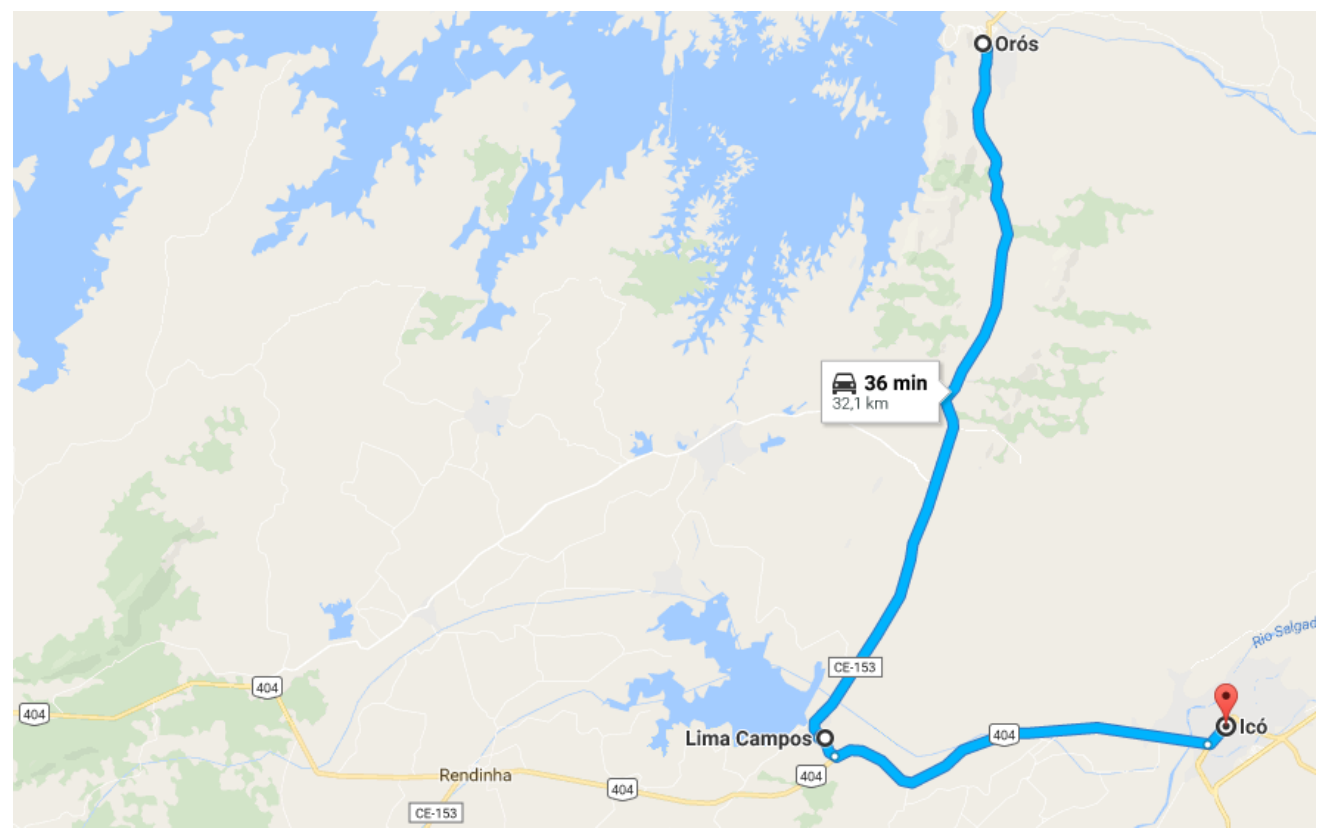

Fonte: GoogleMaps (2017)

Fazendo uma comparação entre a capacidade de armazenamento dos reservatórios aqui colocados percebe-se que a soma das nove bacias hidrográficas de Caxias do Sul corresponde a aproximadamente $3 \%$ da soma dos dois reservatórios que abastecem os municípios de Orós e Icó. 
Inicialmente pode-se confundir as duas situações descritas acima, onde não haveria necessidade de preocupação por parte da população destas duas cidades nordestinas, pois haveria disponibilidade mais que suficiente para consumo humano e para as atividades agropecuárias. Mas as condições climáticas onde estas cidades estão inseridas justificam este cuidado, a SUDENE (Superintendência do Desenvolvimento do Nordeste) caracteriza que o Semiárido "tem como traço principal as frequentes secas que tanto podem ser caracterizadas pela ausência, escassez, alta variabilidade espacial e temporal das chuvas. Não é rara a sucessão de anos seguidos de seca".

Nesta perspectiva verifica-se que em abril de 2011, foi a última vez que o açude Orós teve sua carga máxima, e nestes últimos anos, de 2011 a 2016, a região enfrenta um período de estiagem com chuvas abaixo da média, que para muitos já é pouco, sendo que a média normal é de $830 \mathrm{~mm} /$ ano e no período acima foi verificado uma redução média de $30 \%$. O que faz com que a população fique apreensiva, com a possibilidade da não normalização das chuvas, pois atualmente possui apenas 22,3\%(HIDRO-CE) da capacidade máxima.

Neste sentido algumas ações foram implantadas pelo Ministério da Integração e o DNOCS (Departamento Nacional de Obras Contra a Seca), como o P1MC (Programa 1 Milhão de Cisternas), na busca de armazenamento de água para uma família captar a água da chuva no período chuvoso(inverno) e se manter nos meses de estiagem.

Figura 3: Cisterna de Placa do P1MC

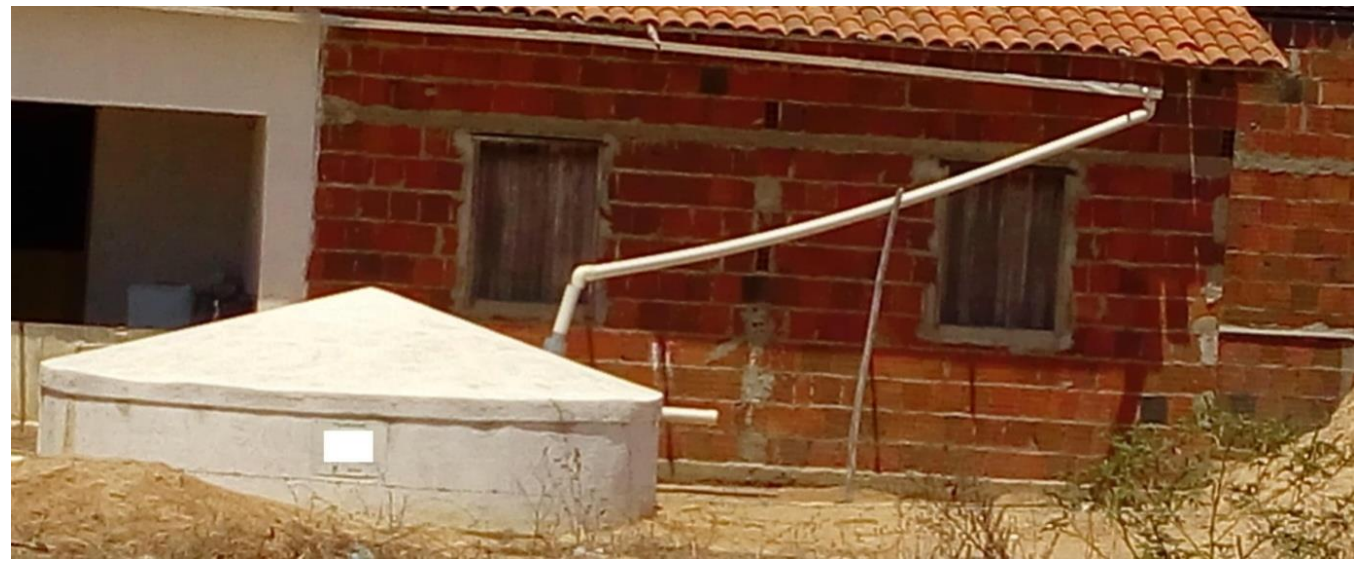

Fonte: Arquivo particular 
Assim a capacidade da cisterna é dimensionada para atender apenas as necessidades básicas como cozinhar e beber. Já para subsidiar a necessidade de água para a produção de alimentos, o Governo Federal implantou a chamada Cisternas de Placa de Produção ou de Segunda Água, pois para ter acesso a esta cisterna a família obrigatoriamente tem que ser atendida pela primeira cisterna para consumo humano.

Figura 4: Cisterna de Placa de Produção

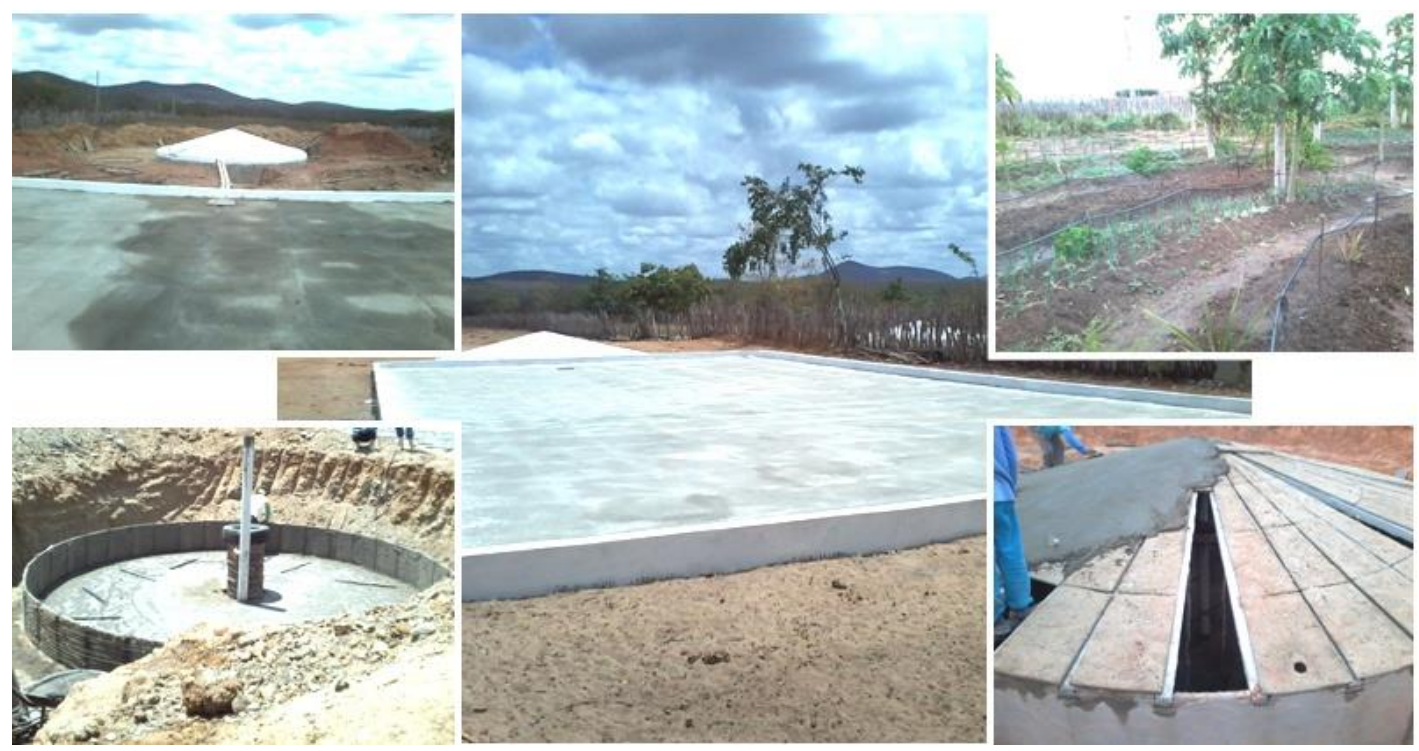

Fonte: Arquivo particular

Conforme verificado nas figuras 2 e 3 as cisternas de placas são capazes de suprir as necessidades básicas das famílias que sofrem continuamente com a estiagem no semiárido brasileiro.

Vale ressaltar que em momentos onde a captação de água não é suficiente para encher as cisternas, alguns municípios disponibilizam caminhões pipas para abastecê-las com águas disponibilizadas nos grandes reservatórios como os Açudes de Orós e Lima Campos.

O Decreto $\mathrm{n}^{\mathrm{o}} 7.535$ (BRASIL, 2011), que instituiu o Programa Nacional de Universalização do Acesso e Uso da Água - “ÁGUA PARA TODOS”, relaciona no seu artigo segundo as diretrizes do programa:

I - priorização da população em situação de extrema pobreza, conforme definido no art. 20 do Decreto no 7.492, de 2011; 
II - fomento à ampliação da utilização de tecnologias, infraestrutura e equipamentos de captação e armazenamento de águas pluviais;

III - fomento à implementação de infraestrutura e equipamentos de captação, reservação, tratamento e distribuição de água, oriunda de corpos d'água, poços ou nascentes e otimização de seu uso; e

IV - articulação das ações promovidas pelos órgãos e instituições federais com atribuições relacionadas às seguintes áreas: a) segurança alimentar e nutricional; b) infraestrutura hídrica e de abastecimento público de água; c) regulação do uso da água; e d) saúde e meio ambiente.

Deste modo, o Governo Federal considera o abastecimento de água, uma necessidade primordial, tendo prioridade o consumo humano em relação à industria, agricultura e atividades produtivas em geral.

\section{Conclusão}

Assim analisando o comparativo entre as duas regiões aqui abordadas, percebe-se que o planejamento estratégico para enfrentar a problemática de disponibilização de água para a população em grande escala é muito similar, sendo realizada por meio de barragens de cursos d'água, mas com uma peculiaridade com relação ao tamanho destes reservatórios, pois como na região semiárida as chuvas são bem menos abundantes em relação a região Sul do Brasil. Comparando a quantidade de reserva máxima de água por habitante, encontra-se a seguinte proporção $24.945,39 \mathrm{~m}^{3} /$ hab no Ceará e $143,34 \mathrm{~m}^{3} /$ hab no Rio Grande do Sul.

Para Leff (2004), nenhum saber é uno, mas sim multidisciplinar, como o conhecimento ambiental que é ligado a vários pensamentos, num processo interminável de construção de saberes, que orienta ações, gera direitos, produz técnicas, para construir um mundo sustentável. E quando se compara as duas situações, vê-se a junção de conhecimentos, ambas buscando a melhor maneira de lidar com o uso e armazenamento da água.

Quando se relaciona a disponibilidade de água para zona rural, onde no caso da região centro sul cearense não possui canalização direta dos grandes e médios reservatórios de água, a construção de cisternas de placa foi a solução mais viável economicamente falando para a 
solução da problemática que se via há poucos anos atrás, e que ainda existe em algumas localidades de pessoas tendo que percorrer vários quilômetros para buscar água em baldes e latas na cabeça, em muitos casos com qualidade duvidosa.

Deste modo foi verificado que a grande distinção entre as duas regiões está relacionada a dois fatores a seguir:

O primeiro refere-se ao tamanho dos reservatórios, sendo que os da região Nordeste são muito maiores que os da região Sul, uma vez que há a necessidade de armazenamento de água por períodos de estiagem maiores que o Sul.

A segunda questão está na política pública de armazenamento de água para subsistência na área rural, ou em localidades que não dispõe de água potável através de construção de cisternas de placa, para serem abastecidas pelas águas da chuva ou por carrospipa quando as chuvas não são suficientes para o aporte necessário de água para o período seco. Nesta segunda questão insere-se ainda as cisternas de placa chamadas de calçadão, proporcionando a capacidade de produção de alimentos para a subsistência. Sendo que estas cisternas já é uma política difundida em todas as regiões do país, mas tem maior concentração na região nordeste.

\section{Referências}

AÇUDE Lima Campos. DNOCS. Disponível em: <http://www.dnocs.gov.br/ barragens/limacampos/limacampos.htm> Acesso em: 27 fev. 2017.

AÇUDE Orós começou a sangrar. Diário do Nordeste. Disponível em: $<$ http://diariodonordeste.verdesmares.com.br/cadernos/regional/acude-oros-comecou-a-sangrar-1.310265> Acesso em: 27 fev. 2017.

ARRUDA, J.J. A História antiga e contemporânea. 7. ed. São Paulo: Ática, 1977. 472 p.

BARRAGEM Orós. DNOCS. Disponível em: <http://www.dnocs.gov.br/barragens/ oros/ oros.htm> Acesso em: 27 fev. 2017.

BRASIL. Decreto $\mathbf{n}^{\mathbf{0}}$ 7.535/2011: Institui o Programa Nacional de Universalização do Acesso e Uso da Água - "ÁGUA PARA TODOS". Brasília, 2011. Disponível em: <http://www.planalto.gov.br/ccivil_03/_Ato2011-2014/2011/Decreto/D7535.htm>, Acesso em 22 mar. 2017 
CHEMIN, Beatris F. Manual da Univates para trabalhos acadêmicos: planejamento, elaboração e apresentação. 3.ed. Lajeado: Univates, 2015. E-book. Disponível em: 〈http://www.univates.br/biblioteca〉. Acesso em: 10 jul. 2017.

CIDADES@. IBGE. Disponível em: <http://cidades.ibge.gov.br> Acesso em: 26 fev. 2017.

LEFF, E. As aventuras da epistemologia ambiental: da articulação das ciências ao diálogo de saberes. Rio de Janeiro. Garamond, 2004.

Complexidade, Racionalidade Ambiental e Diálogo de Saberes. Educação e Realidade. set - dez de 2009. p 17-24.

LORETO, E.F. Avalisação da qualidade da água de consumo humano em municípios pertencentes às macrorregiões de saúde do estado do Rio Grande do Sul. (dissertação) Curso de Mestrado do Centro Universitário La Salle-UNILASALLE, 2014.

MONITORAMENTO. FUNCEME. Disponível em: <http://www.funceme.br/index.php/ areas/23monitoramento/meteorol\%C3\%B3gico/406-chuvas-di\%C3\%A1rias> Acesso em: 27 fev. 2017.

ORÓS. Google Maps. Disponível em: <https://www.google.com.br/maps/dir/ Or\%C3\%B3s,+CE/Lima+Campos,+Ic\%C3\%B3+-+CE/Ic\%C3\%B3,+CE/@-6.3300148,-

$38.9767902,12 \mathrm{z} / \mathrm{data}=! 3 \mathrm{~m} 1 ! 4 \mathrm{~b} 1 ! 4 \mathrm{~m} 20 ! 4 \mathrm{~m} 19 ! 1 \mathrm{~m} 5 ! 1 \mathrm{~m} 1 ! 1 \mathrm{~s} 0 \times 7 \mathrm{a} 3468$

2cad6d325:0x9fb5b0754767a20b!2m2!1d-38.9156022!2d-6.2446364!1 m5!1

$\mathrm{m} 1$ !1s0x7a36b7beb0dc3d1:0x45a95d3446e1b2ba!2m2!1d-38.9524565!2d-

6.4054358 ! $1 \mathrm{~m} 5 ! 1 \mathrm{~m} 1$ ! $1 \mathrm{~s} 0 \times 7 \mathrm{a} 36711 \mathrm{eb} 762397: 0 x b 7047823 \mathrm{~d} 6204839 ! 2 \mathrm{~m} 2$ !1d-38.8591633!2d-

6.4026236!3e0?hl=pt-BR/> Acesso em: 30 Ago. 2016.

PINTO-Coelho, R.M; Havens, K. Crise nas águas. Educação, ciência e governança, juntas, evitando conflitos gerados por escassez e perda de qualidade das águas. Recóleo Editora, Belo Horizonte, (MG). 2015. 162p.

PITERMAN, A.; GRECO, R.M. A água, seus caminhos e descaminhos entre os povos. Revista APS, v.8, n.2, p. 151-164, jul./dez. 2005.

RECURSOS Hídricos. SAMAE CAXIAS. Disponível em: <http://www.samaecaxias. com.br/Pagina/Index/10044/> Acesso em: 27 fev. 2017.

SEMIÁRIDO. SUDENE. Disponível em: <http://www.sudene.gov.br/acesso-ainforma\%C3\%A7\%C3\%A3o/institucional/area-de-atuacao-da-sudene/semiarido> Acesso em: 27 fev. 2017.

VOLUME Armazenado - Reservatórios. Portal Hidrológico do Ceará. Disponível em: <http://www.hidro.ce.gov.br/> Acesso em: 27 fev. 2017.

Como citar este artigo (Formato ABNT):

LAVOR, Anna A.A. de; SILVA, Antônio Carlos A. da; RIBEIRO, Mariana E. O.; BARDEN, Júlia E. Vulnerabilidade da População Atingida pela Estiagem no Semiárido Brasileiro: Uma análise do distrito de Lima Campos, Icó-CE. Id on Line Revista Multidisciplinar e de Psicologia, 2017, vol.11, n.37, p. 271-283. ISSN: 1981-1179.

Recebido: 18.08 .2017

Aceito: 21.08 .2017 